\title{
De la crónica periodística al libro: Cuarenta días en la Exposición (1900), de Emilia Pardo Bazán
}

\author{
María Isabel Jiménez Morales \\ (UNIVERSIDAD DE MÁLAGA) \\ jimor@uma.es
}

(recibido xullo/2017, revisado outubro/2017)

RESUMEN:Emilia Pardo Bazán viaja a París en agosto de 1900 para asistir, como cronista, a la Exposición Universal que allí se celebra. En consecuencia, publica treinta y ocho crónicas en El Imparcial -del 10 de agosto al 3 de diciembre-, que, antes de que finalice 1900, publica en formato de libro bajo el título de Cuarenta días en la Exposición. En el presente artículo me centro, especialmente, en la génesis llevada a cabo por la autora para convertir sus artículos periodísticos en libro. Tras acotar su estancia en París, analizo la diferente estructura de ambos moldes, la transmisión textual del libro, que se editó sin fecha, y describo sus características: el eclecticismo, la erudición, el enfoque subjetivo y, sobre todo, el altísimo componente crítico. Analizo también las diferencias de esta obra con respecto a sus anteriores libros de crónicas: $A$ I pie de la Torre Eiffel y Por Francia y por Alemania.

PALABRAS CLAVE: Emilia Pardo Bazán, Exposición Universal de París 1900, Crónicas periodísticas del siglo XIX, Literatura de viajes, Cuarenta días en la Exposición.

ABSTRACT: Emilia Pardo Bazán travels to Paris in August 1900 to attend, as chronicler, at the World Exposition. As a result, she publishes thirty-eight chronicles in El Imparcial, from August 10 to December 3. Before the end of 1900, she publishes in book format under the title of Forty Days at the Exposition. In this paper, I focus, especially, in the genesis carried out by the author to convert his journalistic articles in book. After narrow their stay in Paris, I analyze the different structure of both molds (book and chronicles), the textual transmission of the book, which it was published without date, and I describe its characteristics: eclecticism, erudition, the subjective approach and, above all, the very high critical component. I also analyze the differences of this work with regard to his earlier books of chronicles: At the foot of the Eiffel Tower and By France and Germany.

KEY WORDS: Pardo Bazán, Emilia, Paris Universal Exposition 1900, Journalistic Chronicles, Travel Literature, Forty Days at the Exposition.

En agosto de 1900, Emilia Pardo Bazán viaja a París como cronista de la Exposición Universal que allí se está celebrando. Durante su estancia, envía crónicas sobre el certamen a El Imparcial, periódico madrileño que podía divulgar convenientemente en España dicho acontecimiento. No era esta la primera exposición que visitaba la escritora, pues, como curiosa viajera, había asistido a la Universal de Viena en 1873 y a la de Barcelona, en 
1888; sin olvidar que un año después, en el centenario de la toma de la Bastilla, visitaba la Exposición Universal de París, como cronista de varios medios hispanoamericanos. En esta ocasión, Pardo Bazán recopilaba sus recuerdos parisinos en dos libros titulados Al pie de la Torre Eiffel. (Crónicas de la Exposición) (1889) y Por Francia y por Alemania (1890) ${ }^{1}$. En 1900, acudía nuevamente a París y de sus crónicas periodísticas nacería un nuevo libro: Cuarenta días en la Exposición, con el que, a juicio de Freire López (1999: 207), Pardo Bazán alcanza la madurez como cronista ${ }^{2}$.

La Exposición de 1900 abrió sus puertas el 15 de abril y se clausuró el 12 de noviembre. Rendía homenaje al siglo que finalizaba y celebraba el nacimiento de uno nuevo, rico en descubrimientos y en avances técnicos, caracterizado por el espíritu de la modernidad. En numerosas ocasiones, Pardo Bazán advierte a los lectores de ello. Al final de la primera crónica, cuando la autora se encuentra de viaje entre León y Venta de Baños, antes de parar en San Sebastián, anticipa el objetivo de esta nueva exposición: “¡Voy en busca de algo que se parece tan poco a estas antiguallas hermosas! Voy hacia la vida moderna, hacia las últimas revelaciones de la industria, de la ciencia, de la realidad" (Pardo Bazán 1900: 10). Pero, aparte del componente tecnológico, de los avances de la física, la microbiología o la electricidad, por citar solo algunos, la Exposición que visita Pardo Bazán es escaparate de las nuevas ideas artísticas que se extienden por Europa y que se dejan ver en numerosos edificios del recinto y en la propia puerta de entrada, obra de Binet. Este nuevo estilo artístico, con rasgos bizantinos y orientales, es el de toda la Exposición, al que la autora dedica numerosas palabras de admiración en sus crónicas, que han sido estudiadas por C. Núñez Rey (2015: 175-180).

Como la de 1889, volvía a ser una Exposición polémica. No conmemoraba ninguna efemérides concreta, pero el hecho de que Francia y Alemania, dos primeras potencias europeas, pugnaran con cierta acritud por ser la sede de un acontecimiento de tanta repercusión internacional ayudó a crear cierto clima de tensión. El certamen suscitó, a su vez, disparidad de opiniones: "para unos, fracaso ruidoso a la faz de Europa; para los otros, brillante fecha en los anales de Francia" (Pardo Bazán 1900: 23). Antes de iniciar su viaje, Pardo Bazán informa que en España había una sensación generalizada de escaso éxito del certamen, que se reflejaba en situaciones tan nimias como la reventa de tiques. Con gran sagacidad, apunta que estos se habían convertido en particular papel moneda del certamen, cuya fluctuación en el precio era indicio del éxito del mismo ${ }^{3}$. Pero, inmediatamente, ese rumor de fondo dejó de sonar en nuestro país, forjándose los españoles una nueva impresión. Pardo Bazán cree, con orgullo, que contribuyó a ello,

\footnotetext{
1 Para el estudio de estas dos obras, vid. M. I. Jiménez Morales (2008 y 2009). Con carácter general, también fueron estudiadas por A. M. Freire López (1997 y 1999), J. M. González Herrán (2000: 50-52), N. Carrasco Arroyo (2007) y J. Morillo Morales (2015: 460-487).

2 E. Ruiz-Ocaña Dueñas (2007: 118-126) intenta elaborar en su estudio el canon periodístico de la autora y analizar las diferencias entre artículo y crónica.

3 "Son los tickets, un papel moneda, que se cotiza en Bolsa con altibajos: el precio oficial es de un franco, pero hay días que se compran a veinticinco céntimos, y se cree que al final de la Exposición valdrán a cinco" (Pardo Bazán 1900: 29).
} 
"auxiliada eficazmente por la enorme publicidad y circulación del gran diario madrileño en que mis crónicas se imprimían" (Pardo Bazán 1900: 278)

La escritora gallega inicia su viaje desde A Coruña a París el 4 de agosto, con paradas en León, Venta de Baños y descanso en San Sebastián al día siguiente, para poder tomar el lujoso sudexpreso, de tantas resonancias literarias para la autora, el 6 de agosto ${ }^{5}$. Tras doce horas de viaje -pasando por San Juan de Luz, Biarritz, Bayona, Dax y Burdeos-, Pardo Bazán llega a la recién inaugurada Estación Orsay ese mismo día por la noche, tal y como afirma Ángel María Castell (6-8-1900: 1) ${ }^{6}$. Así lo relata también la autora en sus primeras crónicas de El Imparcial del 10, 16 y 17 de agosto, respectivamente, donde detalla su largo y fastidioso periplo en ferrocarril. Diserta en estas tres entregas iniciales sobre las incomodidades del viaje y ciertos problemas materiales que le ocasionaron varias contusiones y un mareo colosal. Nada relativo al desarrollo de la Exposición, pero interesante para conocer las condiciones de los viajeros en el comienzo del siglo. En este sentido, estas tres crónicas enlazan con las recopiladas en Mi romería, donde la autora también dedica numerosas reflexiones al hecho material de viajar (Jiménez Morales 2007: 166-167). Resulta curioso que El Imparcial recogiera estas primeras tres crónicas con tanto retraso, publicándose la última casi dos semanas después de iniciado su viaje.

Pardo Bazán visita la Exposición cuando Ileva casi cuatro meses inaugurada. Extraña su tardanza en llegar a París, pues en la de 1889 la propia escritora presencia la fiesta inaugural. La justificación quizá habría que encontrarla en la precipitación con que, en 1900, se abre el nuevo certamen y en la demora que experimentaban las obras. Alberto Mar es quien con más detalle narra los primeros meses de la Exposición, el retraso de todas las instalaciones y el descrédito e impopularidad que de ello resultó para el certamen: "Cuando se considera que el 15 de abril estaba todo el inmenso recinto lleno de baches, de maderajes, de montones de yeso, y que casi no había una instalación terminada; [...] no es de extrañar que durante tres meses solo se oyeran lamentos y gemidos" (30-10-1900: 250). Este periodista sigue comentando que todavía a mediados de agosto "estaba París vacío" y que únicamente se vieron forasteros desde esta fecha hasta el final de la Exposición. Las páginas de La Ilustración Española y Americana daban cuenta de uno de los desgraciados

\footnotetext{
4 A juicio de B. M. Hernando (2015: 14), uno de los hitos que marcan la actividad periodística de Pardo Bazán es, precisamente, su participación en El Imparcial, que culmina como enviada especial a la Exposición de 1900. E. Pérez Romero estudia las colaboraciones de doña Emilia en este diario (2016: 35-40), con especial atención a sus crónicas de viajes por España y Europa (36-39). También fue abordado su trabajo en El Imparcial por Freire López (2003: 126-127) y por Thion Soriano-Mollá (2014).

5 El 29 de septiembre de 1902 Pardo Bazán publica en El Imparcial un cuento que toma el nombre de dicho tren: “Sud-exprés”. En 1909, inaugura con él un nuevo libro de relatos que llevaría en portada su título: Sud-exprés. Cuentos actuales y que ocuparía el volumen XXXVI de sus Obras completas.

6 Á. M. Castell, corresponsal de El Imparcial, precisa que el 5 de agosto Pardo Bazán había llegado a San Sebastián procedente de A Coruña en el primer expreso y que a la mañana siguiente continuaría viaje a París, teniendo prevista su llegada a la capital francesa esa misma noche.

"San Sebastián 5 (9,50 noche)

En él [el bulevar] encontré varias personas conocidas, entre ellas doña Emilia Pardo Bazán, que llegó en el primer expreso. Acababa de visitar a sus amigos los marqueses de La Laguna y se dirigía a casa del alcalde, Conde de Torre Múzquiz, a almorzar. Me dijo que se había detenido a descansar y que mañana, en el sudexpreso, sigue a París, desde donde escribirá crónicas de la Exposición para El Imparcial”.
} 
accidentes sucedidos en el recinto por aquellos días iniciales, donde fallecieron veinte trabajadores, informando a los lectores que las obras aún no estaban terminadas y que, probablemente, no lo estarían antes del mes de julio: "El 14 de abril se inauguró pomposamente la Exposición... por hacer...", bromeaba A. Mar (8-5-1900: 266). De hecho, las primeras fotos publicadas en esta revista ofrecen una imagen poco halagüeña del certamen: obras, escombros, escalas, grúas... Esa sensación de provisionalidad debió calar en el ánimo de los futuros visitantes, sobre todo extranjeros. De ahí que Ramón Asensio Mas (28-4-1900: 237), corresponsal de Madrid Cómico para la Exposición, escriba un poema donde alude al retraso y previsible fracaso de la misma:
que en la carta siguiente
hablaré de París, de las francesas,
(que por cierto, señores,
las hay muy superiores)
y de la Exposición inaugurada
con pompa excepcional el otro día,
Exposición apenas visitada
porque en ella no hay nada...
no han llegado los muebles todavía.

Además de estos argumentos, debió de influir en su decisión su experiencia personal tras la visita a la anterior exposición parisina de 1889. En una carta dirigida a Ortega Munilla días antes de iniciar su viaje, la autora considera el mes de agosto el más idóneo para ello: "Se acerca el mes de agosto y me parece el más a propósito para ir a París y escribir las crónicas destinadas a ese diario". Y con su sagacidad habitual, concluye: "Es mes en que la política duerme y las noticias escasean: yo creo que es tiempo a propósito" (Thion Soriano-Mollá 2014).

En París, Pardo Bazán se aloja en el Hôtel du Louvre. C. Núñez Rey (2015: 168) apunta la posibilidad de que al poco de llegar a la capital francesa la autora se instala en el Hôtel Regina, recientemente inaugurado ${ }^{7}$. No se sabe con certeza la duración de su estancia en París. La periodicidad y distribución de sus artículos -se publican mayoritariamente entre agosto y septiembre de $1900{ }^{8}$ y el título del libro recopilatorio de estas experiencias: Cuarenta días en la Exposición, induce a pensar que Pardo Bazán estuvo en la capital francesa desde el 6 de agosto hasta mediados o finales de septiembre. Personalmente, me inclino a pensar que permaneció hasta los últimos días del mes, por las menciones

\footnotetext{
${ }^{7}$ Sin embargo, una de las cartas editadas por D. Thion Soriano-Mollá (2014), la $\mathrm{n}^{\circ} 4$, que dirige la escritora gallega al director de El Imparcial y que está fechada en París el 20 de septiembre, presenta el membrete del Grand-Hôtel du Louvre. Puede que conservara papel timbrado del primer hotel y que ya no se alojase en él, pero es un dato a tener en cuenta.

${ }^{8}$ De los treinta y ocho textos remitidos al diario madrileño, once se publicaron en agosto y diecinueve en septiembre. Las ocho restantes entregas se repartieron de la siguiente manera: cinco, en octubre; dos, en noviembre y una, en diciembre.
} 
esporádicas de la autora, siempre alusivas a los meses estivales y sobre todo a septiembre. Empleo el calificativo de "esporádicas", pues en sus crónicas aparecen -a diferencia de sus anteriores libros de viajes- escasas noticias y datos cronológicos precisos que arrojen luz sobre su estancia en el certamen y que ayuden a concretar la duración de su visita.

Si nos centramos en la crónica de la Exposición, los datos sobre la autora son exiguos. En primer lugar, hay que mencionar el homenaje que un grupo de admiradores rinde a Balzac el 18 de agosto en el cincuenta aniversario de su muerte y al que Pardo Bazán acude acompañada, entre otros, de Rodin. Sabemos con certeza que la escritora gallega asiste al "Congreso Feminista de la Condición y Derechos de la Mujer", que se celebra del 5 al 11 de septiembre. Concurre a dicho evento delegada, no por el gobierno español, sino por su propia curiosidad ${ }^{9}, \mathrm{y}$, como una de sus actividades programadas, visita el Palacio del Traje, que le impresiona muy favorablemente ${ }^{10}$. Asimismo, en septiembre asiste al Teatro Loïe Fuller para ver Kesa, drama protagonizado por la actriz Sada Yacco ${ }^{11}$. Desconozco el día exacto de esta representación, pero en su crónica "Atracciones", publicada el 20 de septiembre en el diario madrileño, indica que ya ha visto dicha obra, y que, a su juicio, solo hay en la feria de la Exposición cuatro "atracciones" verdaderas y dignas de interés: "la Casa Suiza, el Palacio de la Óptica, el del Traje y el Teatro Loïe Fuller, con la compañía japonesa" (Pardo Bazán 1900: 185). Si se toman al pie de la letra sus afirmaciones, vuelve a confirmarse que en septiembre todavía permanece Pardo Bazán en París, pues cuando publica su crónica "Belona", el 26 de dicho mes, parece estar presente ante el palacio que describe: "A la vuelta de dos meses, este edificio [...] será un hacinamiento de ripio y polvo" (1900: 166). Teniendo en cuenta que la Exposición se clausuraría el 12 de noviembre, Pardo Bazán se encontraría en París a mediados de septiembre, lo que también queda confirmado por una crónica de "La vida contemporánea", aparecida dos días antes en La Ilustración Artística. Pardo Bazán indica en ella que todavía está en París con un escueto: "mientras yo me paseo por París" (24-9-1900: 2). Todo lo expuesto lo corrobora una carta personal de la autora a Ortega Munilla, fechada en París el 20 de septiembre y escrita sobre una tarjeta del Grand-Hôtel du Louvre. En la posdata, la escritora comunica a su amigo su intención de regresar a España a finales de septiembre: "Como saldré de aquí en la semana próxima" (Thion Soriano-Mollá 2014).

\footnotetext{
9 Juan B. Enseñat informa a sus lectores que en París se celebraron, durante la Exposición, ciento veintidós congresos diferentes. Dos de ellos abordaron el feminismo: el de "Obras e Instituciones Femeninas", que, según Pardo Bazán, tuvo lugar en junio o julio. Enseñat cuenta a este particular que todos los años se celebraba en Versalles un Congreso Feminista, pero que "con motivo de la Exposición [se ha transformado] en un congreso internacional" (10-9-1900: 2). El segundo congreso feminista fue el de "Condiciones y Derechos de las Mujeres", organizado por Marguerite Durand, Clémence Royer y Marie Deraiftmes, que tuvo gran apoyo institucional, y al que asistió la autora gallega.

${ }^{10}$ La propia escritora confirma su asistencia en la crónica titulada "Mujeres": "el Congreso feminista, que ayer terminó sus tareas, cerrándolas con un banquete de más de trescientos cubiertos y tres mil brindis, en el recinto de la Exposición” (1900: 149).

11 De Sada Yako da cuenta elogiosa Fray Cantil en uno de sus artículos de Madrid Cómico (22-9-1900: 407408). La Época publicó un resumen del artículo de Pardo Bazán, sin su firma, el 15 de octubre. Se sabe que esta actriz llega a París el 29 de junio de 1900 y que su primera actuación tiene lugar el 4 de julio (Ruedas de la Serna 2006: 31).
} 
Rastreando en la prensa contemporánea, he localizado un anuncio, anterior al aportado por C. Núñez Rey (2015: 166), que parece acotar su estancia parisina y que ayuda a datar su regreso a España. La profesora refiere el homenaje que el Círculo de Artesanos le dedica en A Coruña el 11 de noviembre y que recoge un anuncio de El Imparcial dos días después ${ }^{12}$. Pero el diario La Época publica a principios de octubre una noticia que informa de la reciente marcha de Emilia Pardo Bazán de París ${ }^{13}$. Este breve comunicado indicaba que doña Emilia, tras haber dado por finalizada su labor de cronista en la Exposición, había visitado a la duquesa de Cánovas del Castillo -que se encontraba en San Juan de Luz desde hacía algunos días- y que, juntas, se habían trasladado a Biarritz a dar el pésame a la duquesa de Osuna ${ }^{14}$. Teniendo en cuenta que las noticias podían publicarse algunos días después de lo anunciado, con total certeza puede decirse que Pardo Bazán había abandonado París a finales de septiembre y es previsible que a principios de octubre ya se encontraba en España.

Después de este obligado preámbulo, relativo a la duración y al hecho material de su viaje, comenzaré el análisis de las crónicas periodísticas, incidiendo en su génesis: desde que se formaliza el contrato con El Imparcial, ven la luz en este diario madrileño y se recopilan en libro. Gracias a D. Thion Soriano-Mollá (2014), al publicar algunas cartas remitidas por doña Emilia a Ortega Munilla, sabemos que la escritora gallega marchó a París con un encargo claro de El Imparcial y que firmó con este diario una cláusula de exclusividad $^{15}$. La carta número 4 que reproduce D. Thion en el anexo de su artículo (2014) está fechada en A Coruña el 24 de julio. En ella confirma este particular la autora: "Claro es que en estas condiciones yo respeto la exclusiva al Imparcial". Y para que esta sea completa "y no necesite acudir a llevar la representación de ningún diario de Madrid, ni siquiera nominalmente", Pardo Bazán le ruega a su destinatario que escriba a Alejandro Mar para que la reconozcan en París "como enviado extraordinario del Imparcial", con la idea de poder obtener la entrada gratuita en la Exposición. Desconozco cuál fue el motivo por el que la autora no obtuvo el citado pase. Si hacemos caso de sus palabras, debió influir, en primer lugar, cierta desidia de la autora: "Yo podría prescindir del ticket si solicitase el pase de periodista. No lo hago merced a esa pereza española ante el ahorro pequeño, de la cual me reconozco inficionada". Pero tampoco hay que olvidar un argumento de peso: el excesivo papeleo exigido por la organización del evento: "Era preciso fotografiarse en casa de Nadar, y supongo que Ilenar algunas fórmulas en la comisaría". En consecuencia, la escritora zanja el asunto comprando un montón de entradas: "Me quedo de simple mortal,

\footnotetext{
12 Ese mismo banquete fue anunciado también en La Ilustración Española y Americana el 15 de noviembre de1900.

13 Vid. la sección "Viajes" de La Época del 5 de octubre.

14 Asimismo, el 26 de septiembre de 1900 aparecía en el mismo diario otra noticia bajo la sección de "Viajes" donde se anunciaba que la duquesa de Cánovas del Castillo ya se encontraba en San Juan de Luz. Por tanto, la visita de Pardo Bazán a la duquesa y, en consecuencia, su salida de París tuvo que ser posterior a esta fecha.

15 La autora confirmaba esta exclusiva en uno de los artículos de "La vida contemporánea”: “Creo que estas desazones por ceremonial [alude a cuestiones de protocolo] es lo único que de particular ocurre en mi patria, mientras yo me paseo por París y describo en El Imparcial la Exposición. Solo allí hablo de ella" (Pardo Bazán 24-9-1900: 2).
} 
y un viejo de aspecto pobrísimo y limpio, uno de esos mendigos decentes de París, me vende un puñado de tickets" (Pardo Bazán 1900: 29).

En cartas previas debieron abordarse las condiciones económicas y contractuales, pues la escritora confirma a Ortega: "Yo estoy conforme en el precio de las crónicas". Solo pone como condición que El Imparcial publique, "de manera que resulte lucida la campaña", al menos quince o veinte crónicas. Sus palabras evidencian el deseo de disponer de suficiente libertad de maniobra para no tener que solicitar continuos y engorrosos permisos y plazos al periódico: "No respondo de poder escribirlas, pero quiero tener la facultad de hacerlo sin que sea para Vds. una molestia" (Thion Soriano-Mollá 2014).

Esto lo escribe a finales de julio, antes de emprender viaje a París. Cuando ya lleva mes y medio en el país vecino y su estancia allí está a punto de concluir, vuelve a escribir a Ortega Munilla con un ruego: que, si la campaña en ese periódico "no ha cansado al público", le dejen seguir enviando crónicas: "todavía una docena de artículos más, que lo redondeen". A 20 de septiembre, fecha de la misiva, Pardo Bazán había publicado veinticinco crónicas en El Imparcial, sobrepasando en cinco la idea pactada inicialmente. Con esta nueva petición y si el director del periódico aceptaba su propuesta, cerraría el ciclo y sus crónicas ascenderían a un total de treinta y siete. Si añadimos el último texto de Pardo Bazán que hacía balance y resumen de su labor en París, contamos con el número exacto de crónicas que realmente publicó en El Imparcial. Se comprueba cómo el trabajo periodístico era en aquellos años dinámico y vivo, dependiente en todo momento de los gustos e intereses de la opinión pública, del vaivén de los acontecimientos contemporáneos y, por supuesto, de la dirección de los periódicos. Un proyecto inicial que no superaría las veinte crónicas, vemos cómo llega a duplicarse. Pardo Bazán intenta convencer al director de El Imparcial con unas escuetas y sinceras palabras: "es tanto y tan bueno lo que aquí hay que ver y contar". Y continúa explicando a Ortega Munilla: "No he hablado aún de Guerra y Marina, ni de la pintura, ni de las joyas", se justifica; dejando abierta la posibilidad de seguir incluso con su labor, si lo considera oportuno el periódico:

Creo que estos artículos no serán indiferentes y entretendrán a los lectores. Con ellos terminará mi campaña, a no ser que Vds. quisieran que continuase; pero supongo que, dentro del interés periodístico, que suele ser desflorar los asuntos, preferirán que cese. Vds. dirán. (Thion Soriano-Mollá 2014).

La petición de la escritora fue aceptada y hasta mediados de noviembre aparecieron en El Imparcial doce nuevas crónicas (las que pedía en su carta de septiembre). Repitiendo las sugerencias de su epístola, escribió, en efecto, sobre "Guerra y Marina" - "Belona" (26 de septiembre)-; sobre pintura -"Retratistas" (5 de noviembre) e "Historia y paisaje" (19 de noviembre)- y sobre joyas -"Las joyas" (12 de octubre)-. Pero también publicó crónicas que recogían su admiración por la actriz Sada Yacco -“Un drama japonés”, del 15 de octubre-; sobre la propaganda evangélica de las escuelas religiosas en Francia -“Las misiones católicas" (24 de septiembre)-; sobre caza y pesca en el "Palacio de la Naturaleza" (22 de octubre); sobre infraestructuras urbanas -"Al Duque" (25 de septiembre)-; escultura -"Muñecos franceses" (21 de septiembre), "Muñecos internacionales" (28 de septiembre) 
y "Muñecos insurrectos" (20 de octubre)- y sobre los avances de la microbiología: "Otro busto" (23 de octubre). A todas estas nuevas crónicas, añadió una última: "Balance", que, a principios de diciembre, recapitulaba todo lo visto y aprendido en París. De este modo, la autora volvía a caldear el ambiente y captaba posibles lectores interesados en el libro recopilatorio de estos textos que, como veremos más adelante, acababa de ver la luz en la colección de sus obras completas.

Desde el 10 de agosto al 3 de diciembre, aparecen en El Imparcial treinta y ocho artículos de periodicidad variable, que -salvo las dos últimas entregas- se publican estando abierta la Exposición. La mayoría de las colaboraciones de la autora en El Imparcial a lo largo de 1900 fueron estas crónicas. Antes de su viaje a París solo había publicado tres cuentos y dos artículos de crítica literaria ${ }^{16}$. Todas estas crónicas se incluyen en la etapa periodística que Pérez Romero califica "de consolidación y consagración" de la escritora gallega. La crónica "en sus diferentes modalidades se convierte en el género por antonomasia de su práctica periodística" (Pérez Romero 2016: 163). Excepto la del 15 de octubre -“Un drama japonés"-, todas ven la luz bajo un epígrafe unificador. Las tres primeras se publican con el de "Hacia la Exposición", que acertadamente hace alusión al viaje que la autora acaba de emprender desde su tierra natal; y las restantes se agrupan bajo el título de "En la Exposición". Pero, pese a este subtítulo y a raíz de mis pesquisas sobre su fecha de regreso a España, apunto que las últimas ocho crónicas -las correspondientes a los meses de octubre, noviembre y diciembre- se publican estando la autora ya en España ${ }^{17}$. Pardo Bazán siguió remitiendo crónicas a El Imparcial, como si se encontrase en el país vecino. No era la primera vez que obraba de este modo, ya que en la Exposición de 1889, queda comprobado que la autora enviaba cartas al periódico que escribía desde Madrid o A Coruña y que ella fechaba en París. Tomaba apuntes sobre el certamen que luego elaboraba en España (Carrasco Arroyo 2007: 341-342; y Jiménez Morales 2008: 516-517). Ahora, en 1900, emplea el mismo sistema.

Al dar un subtítulo común a sus crónicas, Pardo Bazán les confiere una relación seriada y una coherencia que facilita su recopilación posterior e independiente del formato periodístico. En su mayoría, estos artículos aparecen en la primera página de $E I$ Imparcial, lo que prueba la relevancia del evento y el deseo del diario madrileño de dar una conveniente publicidad al mismo que le permita competir con otras publicaciones que también se hicieron eco del acontecimiento: La Ilustración Española y Americana, La

\footnotetext{
$\overline{16}$ Los títulos de sus cuentos son: "Justiciero" (12-febrero); "El comadrón" (2-abril) y "El vino del mar" (18-junio). Uno de los artículos de crítica literaria habla de Tolstoi ("Resurrección”, 5 de marzo) y otro sobre D’Annunzio (El fuego, 23 de abril). Todos fueron publicados en Los Lunes de El Imparcial. N. Clemessy aporta la relación de sus colaboraciones en El Imparcial a lo largo de 1900 (1982: 863). También aparece información detallada en C. Alonso (2007: 41-47), quien estudia la labor de Pardo Bazán en Los Lunes de El Imparcial.

17 Cuando escribe su crónica "Retratistas", publicada en el periódico el 5 de noviembre, la autora emplea el pasado para referirse a su estancia en París: "De los días que consagré a la Exposición, una tercera parte se la llevaron las secciones artísticas” (Pardo Bazán 1900: 259). El subrayado es mío.
} 
Ilustración Artística y Madrid Cómico, entre otras ${ }^{18}$. Tal y como puede comprobarse en el Apéndice I de este artículo, de las treinta y seis crónicas que publica estando abierta la Exposición, veintisiete aparecen en la primera plana del periódico. Cuando no sucede así, el desplazamiento de la crónica viene justificado por un acontecimiento de primer orden: la muerte de algún dignatario, un episodio bélico... Es el caso, por ejemplo, de "Las misiones católicas", que se publica en la página 4 del 24 de septiembre, pues toda la portada del periódico fue dedicada a la muerte del general Martínez Campos; o el de la crónica titulada "El palacio de la Naturaleza", del 22 de octubre, cuya primera plana recogía la crisis política española, con la dimisión del gobierno, la guerra anglobóer y la visita a nuestro país de los reyes de Portugal. También me gustaría resaltar el hecho de que hubo seis crónicas que aparecieron en el suplemento de Los Lunes de El Imparcial: "Las misiones católicas", "Un drama japonés", "Otro busto", "Retratistas", "Historia y paisaje" y "Balance". Y solo una de todas las enviadas al diario madrileño -“Un drama japonés"- fue fechada por la autora, indicando expresamente el mes (no el día) de escritura y el lugar: "París, setiembre".

Durante agosto y septiembre, las crónicas tienen una frecuencia más regular. Son los meses en que la autora reside en París. Nunca transcurren más de tres días entre artículo y artículo. Sucediendo con relativa frecuencia que muchos de ellos se publican en días consecutivos. Cuando es así, Pardo Bazán no puede organizar sus crónicas con un orden o esquema prefijados, saliendo de su pluma tal y como se conciben y redactan. Sin olvidar que la amplitud y dimensiones de la Exposición, mucho más grande que la celebrada en 1889: "diez o doce veces mayor, y acaso me quedo corta", afirma la autora, impedían visitar todas las instalaciones, obligando a los asistentes y periodistas a seleccionar:

de antemano, se adquiere el convencimiento de que es imposible ver más de una cuarta parte de esta inmensidad [...] La primer labor que aquí debe realizar el que quiera no aturdirse, es la que preconizaba don Francisco Silvela: la selección. Ver únicamente lo que nos interesa; dejarse resueltamente lo demás. (Pardo Bazan 1900: 30).

La autora informa a sus lectores que, además, la Exposición tenía un enorme anexo en Vincennes, "para dar cabida al material de caminos de hierro, maquinaria, automóviles, aerostáticos, sport, cultivo forestal, salvamento, ciudades obreras, alimentación económica... iyo qué sé!" (Pardo Bazán 1900: 30).

\footnotetext{
18 Los más importantes diarios y revistas españoles siguen de cerca la Exposición de París. En La Ilustración Española y Americana, Gonzalo Reperaz publica un interesante artículo (22-4-1900); pero es Alberto Mar quien inicia una serie de colaboraciones con periodicidad desde el 8 de mayo $\left(\mathrm{n}^{\circ} 17\right.$ de la revista) hasta el 8 de noviembre $\left(\mathrm{n}^{\circ} 41\right)$. Concluye la serie P. de Álava, quien toma el testigo de Mar desde el 15 de noviembre $\left(n^{\circ} 42\right)$, hasta el 30 de dicho mes $\left(n^{\circ} 44\right)$. En Madrid Cómico, Ramón Asensio Mas remite a dicha revista doce colaboraciones, la mayoría en verso, agrupadas bajo el título: "Desde París. (Notas de mi cartera)", desde el 28 de abril $\left(\mathrm{n}^{\circ} 30\right)$, hasta el 21 de julio ( ${ }^{\circ}$ 42). En la Ilustración Artística, donde la autora colaboraba con la serie "La vida contemporánea", hay una sección: "Crónicas de la Exposición de París", que dirige Juan B. Enseñat desde el 8 de enero -todavía no estaba inaugurada- hasta el 26 de noviembre. La crónica de la inauguración se publicó el 14 de mayo de 1900 ( $\mathrm{n}^{\circ}$ 959, p. 314). Para mayor información, vid. la lista de corresponsales aportada por A. B. Lasheras Peña (2009: 403). A su vez, J. Morillo Morales (2015: 569-570) aporta interesantes datos referentes a los libros que se publicaron tras la Exposición de 1900.
} 
Me gustaría poder elaborar una guía que indique al lector el orden en que Pardo Bazán visita los pabellones y espectáculos que Ilaman su atención y elige para escribir sus crónicas. Y con ella, deducir si verdaderamente estas se publican en El Imparcial respetando el orden de sus visitas o si se alejan cronológicamente del momento en que las redacta. El empeño de la autora gallega en no dejar constancia de sus idas y venidas, eludiendo en todo momento la fecha precisa de sus movimientos en París, impide poder realizarla. Solo hay unos pocos artículos que sí pueden rastrearse, aunque no con cierta dificultad. Es este un punto que diferencia estas crónicas de las que escribió tras sus viajes de 1888 -Mi romería- y 1889 -Al pie de la Torre Eiffel y Por Francia y por Alemania-, que, al ser concebidas en formato epistolar, Ilevan indicaciones del día y mes de escritura. La mayoría de sus entregas periodísticas no aportan el dato concreto, salvo por la fecha de publicación en El Imparcial. Hay crónicas, por ejemplo, que no reflejan el momento exacto de su visita, mostrando un considerable desfase cronológico. Ello se aprecia en "Un drama japonés". Sabemos por otros textos suyos que había ido al Teatro Loïe Fuller antes del 20 de septiembre, pero dicha crónica se publica en El Imparcial el 15 de octubre -casi un mes después-. Otros escritos suyos denotan lo contrario. El caso más Ilamativo de inmediatez de la visita y publicación del texto periodístico es "Mujeres". Esta crónica se escribió -si hacemos caso de sus palabras- tras finalizar el Congreso Feminista y apareció en la prensa el 12 de septiembre, al día siguiente de su clausura. Un plazo más adecuado a las comunicaciones de entonces es "Balzac.- Una baja". En este artículo, Pardo Bazán recogía el homenaje al novelista francés y la triste noticia del fallecimiento del pintor Vaamonde en el pazo de Meirás. Su publicación en El Imparcial se realiza justo una semana después: el 25 de agosto ${ }^{19}$.

Pardo Bazán remite sus crónicas al periódico madrileño, pero al mismo tiempo prepara la publicación de estos textos en un libro que titula Cuarenta días en la Exposición ${ }^{20}$. Es consciente del carácter efímero de las crónicas periodísticas, nacidas de una cercana actualidad, y de la dificultad de ser apreciadas por el lector en su conjunto, tras una lectura reposada. A. M. Freire (2003: 118-119) abunda en detalles sobre este particular, pues no era esta la primera vez que Pardo Bazán recopilaba sus crónicas periodísticas en volúmenes que permitieran al lector una interpretación más fina y culta del evento. La aparición del libro era una forma de no perder la oportunidad que le brindaba la reciente clausura del certamen y de perpetuar su enseñanza y el evidente mensaje regeneracionista, ampliamente estudiado por Núñez Rey (2015: 180-195). Como había escrito en la Exposición de 1889, y consciente del raudo envejecimiento de este tipo de artículos: "el

\footnotetext{
19 El 18 de agosto, al regresar a su hotel tras el homenaje literario, la autora recibe un telegrama con la triste noticia de la muerte de Vaamonde. Pardo Bazán escribe un artículo que glosa los dos sucesos y lo publica el sábado 25 de agosto con el título "Balzac.- Una baja". Publicó otro texto reseñando este luctuoso suceso en $L a$ Ilustración Artística de Barcelona (Pardo Bazán 3-9-1900). En esta revista, el novelista al que alude la autora en el título no es Balzac, sino Eça de Queiroz, fallecido el 16 de agosto de 1900.

${ }^{20}$ E. Pérez Romero indica algunas variantes y apreciaciones críticas interesantes sobre el trabajo de lima y revisión de la autora de las crónicas periodísticas al recopilarse en libro (2016: 183-185). Sería, no obstante, muy oportuno investigar en profundidad las supresiones, adiciones o variantes apreciables por parte de la autora; si se produjo una notable actualización de la información en apenas unas semanas o si, por el contrario, se mantuvo la tendencia conservadora.
} 
cronista tiene que aprovechar esa actualidad momentánea y efímera, y servirla a su público calentita, hirviendo, espolvoreada de sal, de azúcar y a veces hasta de pimienta ligera". (Pardo Bazán 1890: 249). Debió trabajar incansablemente, revisando lo ya publicado, pues solo con rapidez evitaría que se olvidaran sus crónicas. De ello da rendida cuenta la autora en una de las notas al pie de su libro. En la entrega que titula "A la puerta", cuando se transforma en el capítulo IV de Cuarenta días en la Exposición, menciona explícitamente el proceso de corrección del material publicado en la prensa cuando le está dando la forma definitiva de libro y nos indica cómo había modificado algunas de sus afirmaciones iniciales:

Al corregir este libro rectifico el concepto. Las comunicaciones eran fáciles en agosto, porque relativamente no se encontraba París atestado. En septiembre acudió más gente y no se podía vivir, ni tomar coches, ni ómnibus, en especial a la salida de la Exposición. (Pardo Bazán 1900: 26).

Cuarenta días en la Exposición ve la luz en la colección de sus Obras completas, en concreto, en el volumen XXI. El libro aparece sin fecha, pero los anuncios publicitarios en la prensa indican que se publica en torno a noviembre de $1900^{21}$. Asimismo, a principios de diciembre aparece en La Correspondencia de España una interesante información: Emilia Pardo Bazán ha tenido la bondad de enviar a su redacción "un folleto titulado Cuarenta días en la Exposición, o sea la serie de artículos que ha publicado en nuestro estimado colega $E$ I Imparcial"22. Y no puedo dejar de mencionar que en el primer volumen de La España Moderna, fechado en enero de 1901, aparece anunciada la publicación de su libro en la sección de "Obras nuevas"23.

El éxito de la obra, sobrevenido por la actualidad del tema y el prestigio de la autora, hace que rápidamente se agote y que vuelva a editarse transcurridas unas semanas. En efecto, antes de finalizar el mes de febrero, El Liberal anuncia que, debido a la popularidad de los libros de Pardo Bazán: "en los escaparates de las librerías acaba de aparecer la segunda edición de los dos últimos: Cuarenta días en la Exposición y sus dos novelas Una cristiana y La prueba" ${ }^{24}$. Insiste en este dato otro anuncio aparecido el 3 de marzo de 1901, donde se informa que acaba de ponerse a la venta una nueva edición "por haberse agotado la primera, del libro Cuarenta días en la Exposición, en el cual se reproducen las interesantes y amenas crónicas que nuestros lectores han saboreado en las columnas de El Imparcial" ${ }^{25}$. Cuarenta días en la Exposición sería reeditado, sin variar número de capítulos ni de páginas, en las sucesivas ediciones de sus Obras completas. Sabemos que

\footnotetext{
21 El dato más antiguo aparece en la sección "Bibliografía”, de la Revista de Archivos, Bibliotecas y Museos, noviembre-1900, vol. IV, p. 699.

${ }^{22}$ La Correspondencia de España, 5-diciembre-1900, p. 4.

23 El 1 de enero de 1901, la revista La España Moderna se hace eco en la sección "Obras nuevas" de la reciente publicación de Pardo Bazán, dando información básica sobre el tamaño, páginas y precio del libro. Vid. tomo 145, 1-enero-1901, p. 206.

24 El Liberal, 27-febrero-1901, p. 3.

25 El Imparcial, 3-febrero-1901, p. 3.
} 
esta obra se reimprimió en vida de la autora en varias ocasiones: en 1908, en la Imprenta de Idamor Moreno y, al menos, una vez más, pues se aprecian diferencias tipográficas y de presentación con otra edición impresa por V. Prieto y Compañía, editores que desarrollaron su labor entre 1910 y $1922^{26}$.

Para concluir este apartado de la transmisión textual de Cuarenta días en la Exposición, me gustaría comentar la reseña que apareció en La España Moderna (Gómez de Baquero 1-4-1901). El crítico, habitual de la sección "Crónica literaria", alaba la obra, perteneciente al periodismo culto y literario, el que, en su opinión, contribuye a la instrucción del lector. Gómez de Baquero destaca la amenidad del libro, la perspicaz observación de la escritora y su solidez de juicio; pero en ningún momento menciona su mensaje regeneracionista. Aplaude el género de la crónica periodística, pues debe decir mucho en breve espacio y con muy pocas razones, que, en todo momento, deben ser inteligibles y claras, impresionando la fantasía y cautivando agradablemente la atención. Todas estas cualidades se dan, a juicio de Gómez de Baquero, en el libro de Pardo Bazán, que "sobresale con mucho de lo que hasta ahora se ha escrito en España acerca de la Exposición de 1900" (1-4-1901: 140).

Cuarenta días en la Exposición incluye todas las crónicas publicadas por la autora en el periódico, más un texto nuevo: "El traje", que, en el libro, ocupa el capítulo XXXIII. Habla de ello E. Pérez Romero (2016: 183). Este nuevo capítulo del libro corresponde a una de sus entregas de la serie "La vida contemporánea", titulada "Excursión retrospectiva" (Pardo Bazán 19-11-1900). Cuando la escribe, ya se había clausurado el certamen internacional, pero la autora todavía no había concluido sus crónicas, que cerraría a modo de balance el 3 de diciembre. Todos los títulos de sus envíos periodísticos se respetan en el libro, pero no sucede lo mismo con el orden de aparición en El Imparcial, que no siempre se mantiene en Cuarenta días en la Exposición. A este respecto, y para evitar un relato excesivamente extenso, pueden verse los apéndices finales. Parece lógico imaginar que Pardo Bazán va escribiendo y publicando sus artículos en el periódico según visita las diferentes instalaciones o siguiendo la oportunidad que le deparan los eventos que se presentan en París, como el homenaje a Balzac, el Congreso Feminista, el gran banquete de los alcaldes franceses, la representación de Kesa... Debe suponerse incluso que se publican sus entregas en fecha cercana al acontecimiento, aunque pudo retrasar el envío de algunos textos, así como la dirección del periódico posponer su publicación, supeditándolas a las noticias nacionales e internacionales recibidas. De los treinta y ocho artículos de El Imparcial, solo mantiene en el libro en idéntica posición los seis primeros, concebidos a modo de preámbulo, y los cuatro últimos -ya se encontraba Pardo Bazán en España-. Aparte de estas, hay dos crónicas: "Clase primera" y "Apretando", que se mantienen en la mediación del libro, al igual que habían aparecido en el ecuador cronológico de sus entregas, ocupando los capítulos XVIII y XIX. Las crónicas restantes sufren cambios de ubicación por

\footnotetext{
${ }^{26}$ Entre las diferencias se cuentan la forma de indicar el orden de los diferentes volúmenes: en números romanos en la primera edición y en arábigos, en la segunda; el tamaño de las mayúsculas del título en portada y cubierta; la inclusión de una orla decorativa al inicio de cada capítulo en la segunda edición y la aparición en esta misma, junto al nombre de la autora, de su título de condesa. La segunda edición se imprimió en Madrid, V. Prieto y Compañía, Editores, s. a. (Pascual Martínez 1994: 379).
} 
parte de la autora, obedeciendo, sin duda, a su deseo de mejorar la estructura interna del futuro libro, al que quiere conferir un orden más coherente.

E. Pérez Romero aborda brevemente este aspecto (2016: 183). Coincido con ella en la decidida voluntad de la autora de otorgar a su libro una distribución de carácter temático. Pero es evidente también que, al agrupar crónicas de idéntico tema, adelanta los textos de carácter crítico y enfoque regeneracionista, y muy en especial todos los relativos a la representación española en el certamen. En Cuarenta días en la Exposición aparecen consecutivos todos los textos que abordan la situación de nuestra patria. Tras los capítulos dedicados a los pabellones de España y Transvaal -VII y VIII, respectivamente-, con los que pretende reflejar el evidente contraste de esos dos países, Pardo Bazán reagrupa y adelanta "La alimentación española", "Rectifico-ratifico", "Vendimiario", "Una dedada de miel" y "Seguimos en España". Estos escritos se sitúan ahora en el libro en los capítulos IX al XIII. Como afirma la propia autora, expresión que cobra aquí todo su sentido: "el mal camino andarlo pronto" (Pardo Bazán 1900: 85). Tras estos capítulos, Pardo Bazán coloca los dos que dedica a la historia de la ropa y otros dos de carácter anecdótico y digresivo -"Cada cual habla de la feria..." y "Balzac.- Una baja"-, que, probablemente, han sido pospuestos en el libro para alejar del lector el ceño adusto, para atenuar su enojo e indignación. Después, vuelve a reagrupar una serie de capítulos nuevamente críticos, donde refleja la situación de la educación, el ejército, los avances de la física y la infraestructura de las ciudades españolas. Tras los textos que dedica a la educación primaria y a la universitaria -"Clase primera" y "Apretando"-, anticipa "Adelante", "Las misiones católicas", "Al

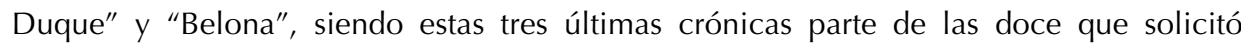
escribir Pardo Bazán a Ortega Munilla para completar la serie. Al ser aceptada su petición, aparecieron en El Imparcial a finales de septiembre -entre el 24 y el 26-, cuando preparaba su regreso a España. Al estar descolgadas de otras crónicas de similares preocupaciones y temas, aprovecha la edición de su libro para ofrecer un orden más coherente.

Al adelantar Pardo Bazán estas nueve crónicas en el libro, tuvo que reubicar las restantes, de tal modo que, a partir del capítulo XXV, aparecen una serie de textos que retroceden en la nueva ordenación del libro. Los casos más Ilamativos son "Naturaleza... con arte", que del lugar 12 en el periódico pasa al capítulo XXV en el libro y, especialmente, "La America latina", del 16 al XXXI. A grandes rasgos, puede afirmarse que, a partir del capítulo XXV, cuando ya han concluido los capítulos más críticos, reúne las crónicas en torno a tres temas principales: las atracciones que ofrece el certamen, el cultivo de las riquezas naturales: caza, pesca... y las diferentes manifestaciones artísticas. Habría en este segundo grupo una curiosa salvedad, la del capítulo XXXI: "La América latina", que parece desentonar en la nueva ubicación, pues es una crónica de crítica contenida, donde aborda la autora el papel activo de muchos países hermanos de América, frente al marasmo e inmovilismo españoles. Estas últimas crónicas respetan, en general, el orden de aparición en ambos moldes, pues fueron en su mayoría las que Pardo Bazán pidió escribir al director de El Imparcial, consideradas como ampliación del conjunto planificado inicialmente.

En las crónicas de 1900 se repiten muchas de las pautas que siguió la autora en Mi romería, Al pie de la Torre Eiffel y Por Francia y por Alemania. Todos estos libros están 
escritos en primera persona, relatan viajes reales, desde una perspectiva personal, tratan de interesar al lector y alejan el dato exhaustivo o tedioso (Morillo Morales 2015: 530). Presentan, no obstante, una diferencia formal apreciable, pues ninguna de sus crónicas de 1900 fue configurada como carta. Este cambio de registro, al alejarse Pardo Bazán del molde epistolar empleado en sus tres libros de viajes anteriores, quizá guarde relación con la aparición a finales de 1899 de la segunda edición de Al pie de la Torre Eiffel y Por Francia y por Alemania en la colección de sus Obras completas, fusionados en el volumen XIX bajo el título unificador del primero ${ }^{27}$. Repetir nuevamente el cauce de la epístola podía resultar para el lector demasiado reiterativo y para la escritora un rasgo de poca originalidad en su trayectoria literaria.

Estas crónicas presentan otra clara diferencia con respecto a las de 1889, pues en su primer viaje como cronista en París, Pardo Bazán retrasó considerablemente el relato natural y físico del certamen. Cuando la Exposición Ilevaba casi dos meses inaugurada, la autora afirmaba que ya iba siendo hora de iniciar la descripción de algunos pabellones. Es entonces -en la entrega XV-cuando comienza por el de Grecia. Ahora, en 1900, no actúa de igual modo: Pardo Bazán entra inmediatamente en materia. Tras las tres crónicas que describen su viaje hacia la Exposición, desde la IV a la VI, empieza a informar sobre las infraestructuras, echa un vistazo general sobre los pabellones... para abordar en la crónica VIII las diferentes instalaciones seleccionadas, comenzando por la representación española y sus distintas contribuciones.

La abundancia de capítulos digresivos de sus anteriores libros disminuye en estas crónicas parisinas, concebidas con un enfoque mucho más serio, reflejo de la profunda crisis que aqueja a España. De hecho, de sus treinta y ocho artículos, solo incluye uno claramente digresivo: "Balzac.- Una baja", donde la autora descansa brevemente del bullicio de la Exposición y relata su viaje a Ville d'Auvrey. Ahora, apenas reseña diversiones. Las únicas excepciones son "Atracciones" y "Un drama japonés". Por las peculiares circunstancias históricas, políticas y económicas de España, Pardo Bazán escribe una obra en la que apenas tiene cabida la digresión: "he procurado condensar y abreviar, por ser la tela mucho más larga que las hechuras" (Pardo Bazán 1900: 277), aclara al final del libro, y porque, como confiesa al principio de su visita, ha ido a París "prefiriendo desde el primer instante hacer resaltar su carácter educador antes que sus atracciones de feria y de espectáculo cosmopolita" (Pardo Bazán 1900: 23). También hay que resaltar la menor presencia de la autora, su invisibilidad conscientemente buscada. En 1900, apenas hace confidencias personales. Cuando aparecen, se localizan especialmente en las tres primeras crónicas, preámbulo a su estancia parisina. No repito los datos que

\footnotetext{
${ }^{27}$ En efecto, la segunda edición de Al pie de la Torre Eiffel y de Por Francia y por Alemania aparece sin fecha en sus Obras completas y con el título de Al pie de la Torre Eiffel. Como ha dejado sentado M. I. Jiménez Morales (2008: 515), puede datarse su publicación en torno a octubre de 1899.
} 
dejó Pardo Bazán en estos textos y remito a C. Núñez Rey (2015: 167-170), quien lo ha estudiado convenientemente ${ }^{28}$.

Sí contemplamos, sin embargo, a la escritora en su faceta profesional de cronista, dirigiéndose a los lectores con frecuencia, apostrofándolos, dando sensación de complicidad y cercanía: "No me preguntéis los kilómetros que mide", les dice refiriéndose a la Exposición (Pardo Bazán 1900: 30), “Se admirarán del mal humor que traigo...?", "¿Querrán ustedes creer...?". Otras veces, les informa de detalles curiosos, como en "Un poco de arquitectura", cuando "un aficionado" se entretuvo en estudiar los tejados de los edificios de la Exposición, maravillado por su variedad y simbolismo; o les comunica noticias de primera mano: "Me aseguran que se venden poco los trabajos de Éibar" (Pardo Bazán 1900: 78). En otros momentos de su crónica, reproduce en estilo directo las ideas que escucha a los asistentes, especialmente acres cuando visita el pabellón de España. Se hace eco, incluso, de muchas sugerencias, peticiones e información de lectores interesados que le escriben. Al ser mucho su trabajo y poco el tiempo libre del que dispone en París, no puede contestar personalmente a sus interlocutores, pero incluye algunas de sus solicitudes directamente en sus crónicas, estableciendo, de este modo, un diálogo implícito con el lector $^{29}$. Y, por supuesto, apunta que le escriben compatriotas que leen sus crónicas y denuncian, por ejemplo, obstáculos que reciben algunos productos españoles para que no se conozcan en París (Pardo Bazán 1900: 88). Como apuntó Pérez Romero, la escritora es consciente del relevante papel que el lector desempeña en el nuevo periodismo, siendo la principal razón de su escritura (2016: 129-133).

La escasez de excursos ajenos al certamen y la disminución del elemento autobiográfico y subjetivo pueden ser valoradas como una lógica consecuencia de las numerosas críticas que diez años antes recibiera a raíz de la publicación de Al pie de la Torre Eiffel y Por Francia y por Alemania, especialmente de Clarín y de Antonio Díaz Benzo, quienes afearon duramente la excesiva presencia de la autora y las abundantes digresiones de todo tipo (Jiménez Morales 2008: 513-515). No debemos tampoco olvidar que las circunstancias de España son ahora mucho peores que hace una década. La autora es consciente de ello y empapa sus crónicas de un claro mensaje regeneracionista, de componente educativo y pragmático que sustituye al elemento personal y subjetivo. El elevado compromiso social y el claro deseo de europeísmo que deja ver en Cuarenta días en la Exposición convierten a esta obra en un libro importante en la trayectoria literaria de Emilia Pardo Bazán, a tener en cuenta para conocer mejor su evolución como escritora.

\footnotetext{
28 Aparte de lo mencionado por la profesora en su estudio, la vemos aconsejar sobre la mejor fonda de León y recomendar a los viajeros el chocolate de Astorga (Pardo Bazán 1900: 6); dar su opinión sobre el juego (pp. 14-15) o lamentarse de que el sudexpreso no tenga reservado femenino (p. 18). Pardo Bazán recuerda varios de sus viajes por la geografía española -uno que hizo a Cataluña y Vizcaya (p. 88)- y francesa -al París de la Exposición de 1889 (pp. 218 y 224)- y comenta que su casa está dotada de luz eléctrica (“y nos cuesta más a veces en abril que en enero", p. 147).

29 "Sépanlo los muchos españoles que me escriben acerca de estos artículos, y a quienes no respondo por falta de tiempo, pero que aquí irán encontrando respuesta a sus indicaciones. No caen en saco roto.” (Pardo Bazán 1900: 83).
} 


\section{BIBLIOGRAFÍA}

Alonso, Cecilio (2007): "Literatura y prensa periódica en España en tiempos de Pardo Bazán (1866-1921)", José Manuel González Herrán, Cristina Patiño Eirín y Ermitas Penas Varela (eds.), Emilia Pardo Bazán: el periodismo, A Coruña, Real Academia Galega, pp. 23-73.

Asensio Mas, Ramón (28-4-1900): "Desde París. (Notas de mi cartera)", Madrid Cómico, no 30, p. 237.

Carrasco Arroyo, Noemí (2007): "Emilia Pardo Bazán, periodista y viajera. Las crónicas de la Exposición Universal (1889)", José Manuel González Herrán, Cristina Patiño Eirín y Ermitas Penas Varela (eds.), Emilia Pardo Bazán: el periodismo, A Coruña, Real Academia Galega, pp. 341-348.

Castell, Ángel María (6-8-1900): El Imparcial, p. 1.

Clemessy, Nelly (1982): Emilia Pardo Bazán como novelista. (De la teoría a la práctica), Madrid, Fundación Universitaria Española, 2 vols.

Enseñat, Juan Bautista (10-9-1900): "Crónicas de la Exposición de París. Los congresos", La llustración Artística, n 976, p. 2.

Fray Candil (22-9-1900): "París", Madrid Cómico, no 51, pp. 407-408.

Freire López, Ana María (1997): “Les expositions universelles du XIXème siècle dans la littérature espagnole: la vision d’Emilia Pardo Bazán", Les Cahiers du CICC, 3, pp. 124-133.

Freire López, Ana María (1999): "Los libros de viajes de Emilia Pardo Bazán: el hallazgo del género periodístico", Salvador García Castañeda (coord.), Literatura de viajes. El Viejo Mundo y el Nuevo, Madrid, Castalia, pp. 203-212.

Freire López, Ana María (2003): "La obra periodística de Emilia Pardo Bazán", Estudios sobre la obra de Emilia Pardo Bazán. Actas de las Jornadas conmemorativas de los 150 años de su nacimiento, A Coruña, Fundación Pedro Barrié de la Maza, pp. 117-132.

Gallego Durán, María del Mar y Eloy Navarro Domínguez (eds.) (2007): Relatos de viajes, miradas de mujeres, Sevilla, Alfar.

García Castañeda, Salvador (coord.) (1999): Literatura de viajes. El Viejo Mundo y el Nuevo, Madrid, Castalia.

Gómez de Baquero, Eduardo (1-4-1901): "Crónica literaria", La España Moderna, tomo 148, pp. 137-142.

González Herrán, José Manuel (2000): "Andanzas e visións de dona Emilia (a literatura de viaxes de Pardo Bazan)", Eduga. Revista Galega do Ensino, no 27, pp. 37-62.

González Herrán, José Manuel, Cristina Patiño Eirín y Ermitas Penas Varela (eds.) (2007): Emilia Pardo Bazán: el periodismo, A Coruña, Real Academia Galega. 
González Herrán, José Manuel, Cristina Patiño Eirín y Ermitas Penas Varela (eds.) (2009): La literatura de Emilia Pardo Bazán, A Coruña, Fundación Caixa Galicia-Real Academia Galega.

Hernando, Bernardino M. (2015): "La periodista Pardo Bazán analiza la vida contemporánea", Pilar Palomo Vázquez, Pilar Vega Rodríguez y Concepción Núñez Rey (eds.), Emilia Pardo Bazán, periodista, Madrid, Arco/Libros, pp. 11-23.

Jiménez Morales, María Isabel (2007): “Entre la crónica de viajes y la autobiografía: Mi romería, de Emilia Pardo Bazán", María del Mar Gallego Durán y Eloy Navarro Domínguez (eds.), Relatos de viajes, miradas de mujeres, Sevilla, Alfar, pp. 155-180.

Jiménez Morales, María Isabel (2008): “Emilia Pardo Bazán, cronista en París (1889)", Revista de Literatura, LXX, 140, pp. 507-532.

Jiménez Morales, María Isabel (2009): "Al pie de la Torre Eiffel y Por Francia y por Alemania: algunas notas de Crítica Textual”, José Manuel González Herrán, Cristina Patiño Eirín y Ermitas Penas Varela (eds.), La literatura de Emilia Pardo Bazán, A Coruña: Fundación Caixa Galicia-Real Academia Galega, pp. 389-399.

Lasheras Peña, Ana Belén (2009): España en París. La imagen nacional en las exposiciones universales, 1855-1900, Santander, Universidad de Cantabria.

Mar, Alberto (8-5-1900): "Crónica parisiense. La Exposición Universal de París. Muertos y heridos. Inauguraciones", La Ilustración Española y Americana, n 17, p. 266.

Mar, Alberto (30-10-1900): “Crónica parisiense. La Exposición Universal de París. Diversas estadísticas", La Ilustración Española y Americana, nº 40, p. 250.

Morillo Morales, Julia (2015): Las Exposiciones Universales en la literatura de viajes del siglo XIX, Madrid, UNED.

Núñez Rey, Concepción (2015): “El París universal de 1900 en la mirada de Emilia Pardo Bazán", Pilar Palomo Vázquez, Pilar Vega Rodríguez y Concepción Núñez Rey (eds.), Emilia Pardo Bazán, periodista, Madrid, Arco/Libros, pp. 165-204.

Palomo Vázquez, Pilar, Pilar Vega Rodríguez y Concepción Núñez Rey (eds.) (2015): Emilia Pardo Bazán, periodista, Madrid, Arco/Libros.

Pardo Bazán, Emilia (1889): Al pie de la Torre Eiffel. (Crónicas de la Exposición), Madrid, Est.-Tip. de La España Editorial.

Pardo Bazán, Emilia (1890): Por Francia y por Alemania, Madrid, Est.-Tip. de La España Editorial.

Pardo Bazán, Emilia (1900): Cuarenta días en la Exposición. Obras completas. Tomo XXI, Madrid, Est. Tip. de Idamor Moreno.

Pardo Bazán, Emilia (3-9-1900): "La vida contemporánea. Un novelista.- Un pintor", La llustración Artística, no 975, p. 570.

Pardo Bazán, Emilia (24-9-1900): "La vida contemporánea. Etiquetas.- Teatros", La Ilustración Artística, no 978, p. 2. 
Pardo Bazán, Emilia (19-11-1900): "La vida contemporánea. Excursión retrospectiva", La llustración Artística, nº 986, p. 746.

Pascual Martínez, Pedro (1994): Escritores y editores en la Restauración canovista (1875-1923), Madrid, Ediciones de la Torre.

Pérez Romero, Emilia (2016): El periodismo de Emilia Pardo Bazán, Vigo, Academia del Hispanismo.

Reperaz, Gonzalo (22-4-1900): "La Exposición de 1900", La Ilustración Española y Americana, $\mathrm{n}^{\circ} 15$, pp. 234-235.

Ruedas de la Serna, Jorge (2006): "Prólogo" a José Juan Tablada, En el país del sol, México, Universidad Nacional Autónoma, pp. 17-54.

Ruiz-Ocaña Dueñas, Eduardo (2007): "El canon periodístico de Emilia Pardo Bazán", José Manuel González Herrán, Cristina Patiño Eirín y Ermitas Penas Varela (eds.), Emilia Pardo Bazán: el periodismo, A Coruña, Real Academia Galega, pp. 91-129.

Thion Soriano-Mollá, D. (juin 2014): "Hacia el periodismo moderno: diez cartas de Emilia Pardo Bazán a José Ortega Munilla (EI Imparcial y La Hoja del Lunes)", El Argonauta Español, [en ligne] no 11. [https://argonauta.revues.org/2097?file=1] (Consultado el 2 de junio de 2017). 


\section{APÉNDICES}

\section{TREINTA Y OCHO CRÓNICAS PUBLICADAS EN EL IMPARCIAL}

(Con sus fechas y equivalencias en los capítulos del libro)

\begin{tabular}{|c|c|c|c|}
\hline Fecha & Título & Número & Capítulo \\
\hline 10 de agosto & $\begin{array}{l}\text { "Hacia la Exposición. Quince horas de } \\
\text { parada y catedral" }\end{array}$ & $n^{\circ} 11969$, p. 3. & 1 \\
\hline 16 de agosto & $\begin{array}{l}\text { "Hacia la Exposición. No solo Madrid es } \\
\text { corte" }\end{array}$ & $n^{\circ} 11976$, p. 1 & II \\
\hline 17 de agosto & $\begin{array}{l}\text { "Hacia la Exposición. De San Sebastián a } \\
\text { París en barco de vapor" }\end{array}$ & $n^{\circ} 11977$, p. 2 & III \\
\hline 18 de agosto & "En la Exposición. A la puerta" & no 11978, p. 23. & IV \\
\hline 20 de agosto & "En la Exposición. Golpe de vista" & $\mathrm{n}^{\circ} 11979$, p. 1. & V \\
\hline 24 de agosto & $\begin{array}{l}\text { "En la Exposición. Un poco de } \\
\text { arquitectura" }\end{array}$ & no 11983, p. 1. & VI \\
\hline 25 de agosto & "En la Exposición. Balzac.- Una baja" & no 11984, p. 1. & XVII \\
\hline 27 de agosto & "En la Exposición. La casa de España" & no 11986, p. 1. & VII \\
\hline 28 de agosto & "En la Exposición. La casa del Transvaal" & no 11987, p. 1. & VIII \\
\hline 29 de agosto & "En la Exposición. Ropa vieja" & no 11988, p. 1. & XIV \\
\hline 30 de agosto & "En la Exposición. Ropa nueva" & no 11989, p. 1. & $\mathrm{XV}$ \\
\hline 1 de septiembre & "En la Exposición. Naturaleza... con arte" & no 11991, p. 1. & $\mathrm{XXV}$ \\
\hline 4 de septiembre & $\begin{array}{l}\text { "En la Exposición. La alimentación } \\
\text { española" }\end{array}$ & $n^{\circ} 11994$, p. 1. & IX \\
\hline 5 de septiembre & "En la Exposición. Rectifico-ratifico" & $\mathrm{n}^{\circ} 11995$, p. 1. & $\mathrm{X}$ \\
\hline 6 de septiembre & "En la Exposición. Vendimiario" & no 11996, p. 1. & $\mathrm{XI}$ \\
\hline 7 de septiembre & "En la Exposición. La América latina" & $\mathrm{n}^{\circ} 11997$, p. 1. & XXXI \\
\hline 8 de septiembre & $\begin{array}{l}\text { "En la Exposición. Cada cual habla de la } \\
\text { feria..." }\end{array}$ & n $^{\circ} 11998$, p. 1. & $\mathrm{XVI}$ \\
\hline 10 de septiembre & "En la Exposición. Clase primera" & no 12000, p. 1. & XVIII \\
\hline 11 de septiembre & "En la Exposición. Apretando" & no 12001, p. 1. & $\mathrm{XIX}$ \\
\hline 12 de septiembre & "En la Exposición. Mujeres" & no 12002, p. 1. & XXII \\
\hline 14 de septiembre & "En la Exposición. Arte antiguo" & no 12004, p. 1. & XXVII \\
\hline 17 de septiembre & "En la Exposición. Una dedada de miel" & $\mathrm{n}^{\circ} 12007$, p. 1. & XII \\
\hline 18 de septiembre & "En la Exposición. Adelante" & no 12008, p. 1. & XXI \\
\hline 19 de septiembre & "En la Exposición. Seguimos en España" & $\mathrm{n}^{\circ} 12009$, p. 1. & XIII \\
\hline 20 de septiembre & "En la Exposición. Atracciones" & $\mathrm{n}^{\circ} 12010$, p. 1. & XXVI \\
\hline
\end{tabular}




\begin{tabular}{|c|c|c|c|}
\hline 21 de septiembre & "En la Exposición. Muñecos franceses" & no 12011 , p. 1. & XXVIII \\
\hline 24 de septiembre & "En la Exposición. Las misiones católicas" & no 12014, p. 4. & $x X$ \\
\hline 25 de septiembre & "En la Exposición. Al Duque" & $\mathrm{n}^{\circ} 12015$, p. 1. & XXIII \\
\hline 26 de septiembre & "En la Exposición. Belona" & no 12016, p. 2. & XXIV \\
\hline 28 de septiembre & $\begin{array}{l}\text { "En la Exposición. Muñecos } \\
\text { internacionales" }\end{array}$ & no 12018, pp. 1-2. & XXIX \\
\hline 12 de octubre & "En la Exposición. Las joyas" & no 12032, p. 2. & $X X X$ \\
\hline 15 de octubre & "Un drama japonés" & no 12035, p. 4. & XXXII \\
\hline 20 de octubre & "En la Exposición. Muñecos insurrectos" & no 2040, p. 1. & XXXV \\
\hline 22 de octubre & $\begin{array}{l}\text { "En la Exposición. El palacio de la } \\
\text { Naturaleza" }\end{array}$ & $n^{\circ} 12042$, p. 3. & XXXIV \\
\hline 23 de octubre & "En la Exposición. Otro busto" & $n^{\circ} 12043$, p. 1. & XXXVI \\
\hline 5 de noviembre & "En la Exposición. Retratistas" & no 12056, p. 4. & XXXVII \\
\hline 19 de noviembre & "En la Exposición. Historia y paisaje" & no 12070, p. 3. & XXXVIII \\
\hline 3 de diciembre & "En la Exposición. Balance" & no 12084, p. 3. & XXXIX \\
\hline
\end{tabular}

II

\section{RELACIÓN DE LOS CAPÍTULOS DEL LIBRO}

(Con sus fechas de publicación en El Imparcial)

\begin{tabular}{|l|l|}
\hline I. Quince horas de parada y catedral & 10 de agosto \\
\hline II. No solo Madrid es Corte & 16 de agosto \\
\hline III. De San Sebastián a París en barco de vapor & 17 de agosto \\
\hline IV. A la puerta & 18 de agosto \\
\hline V. Golpe de vista & 20 de agosto \\
\hline VI. Un poco de arquitectura & 24 de agosto \\
\hline VII. La casa de España & 27 de agosto \\
\hline VIII. La casa del Transvaal & 28 de agosto \\
\hline IX. La alimentación española & 4 de septiembre \\
\hline X. Rectifico - ratifico & 5 de septiembre \\
\hline XI. Vendimiario & 6 de septiembre \\
\hline XII. Una dedada de miel & 17 de septiembre \\
\hline XIII. Seguimos en España & 19 de septiembre \\
\hline
\end{tabular}




\begin{tabular}{|c|c|}
\hline XIV. Ropa vieja & 29 de agosto \\
\hline XV. Ropa nueva & 30 de agosto \\
\hline XVI. Cada cual habla de la feria... & 8 de septiembre \\
\hline XVII. Balzac. Una baja & 25 de agosto \\
\hline XVIII. Clase primera & 10 de septiembre \\
\hline XIX. Apretando & 11 de septiembre \\
\hline XX. Las misiones católicas & 24 de septiembre \\
\hline XXI. Adelante & 18 de septiembre \\
\hline XXII. Mujeres & 12 de septiembre \\
\hline XXIII. AI Duque & 25 de septiembre \\
\hline XXIV. Belona & 26 de septiembre \\
\hline XXV. Naturaleza... con arte & 1 de septiembre \\
\hline XXVI. Atracciones & 20 de septiembre \\
\hline XXVII. Arte antiguo & 14 de septiembre \\
\hline XXVIII. Muñecos franceses & 21 de septiembre \\
\hline XXIX. Muñecos internacionales & 28 de septiembre \\
\hline XXX. Las joyas & 12 de octubre \\
\hline XXXI. La América latina & 7 de septiembre \\
\hline XXXII. Un drama japonés & 15 de octubre \\
\hline XXXIII. El traje (Publicada en La Ilustración Artística) & 19 de noviembre \\
\hline XXXIV. El palacio de la naturaleza & 22 de octubre \\
\hline XXXV. Muñecos insurrectos & 20 de octubre \\
\hline XXXVI. Otro busto & 23 de octubre \\
\hline XXXVII. Retratistas & 5 de noviembre \\
\hline XXXVIII. Historia y paisaje & 19 de noviembre \\
\hline XXXIX. Balance & 3 de diciembre \\
\hline
\end{tabular}

